\title{
Late Onset Prosthetic Hip Joint Infection in Two Patients of Rheumatoid Arthritis Treated With Etanercept
}

\author{
Hayashi SHINYA, Sakai YOSHITADA, Fujishiro TAKAAKI, Hashimoto SHINGO, \\ Kanzaki NORIYUKI, Kuroda RYOSUKE, Kurosaka MASAHIRO \\ Department of Orthopaedic Surgery, Kobe University Graduate School of Medicine, Kobe, Japan
}

\begin{abstract}
In this article, we report two rheumatoid arthritis (RA) patients who developed rare, late onset infection after total hip arthroplasty (THA) following etanercept therapy. First patient was a 74-year-old female with RA. Treatment with etanercept was initiated three years after THA, and infection involving THA was observed two months after the initiation of etanercept. Patient was successfully treated by open debridement. Second patient was a 62-year-old female with RA. THA was performed, and infection involving THA was observed four years after the initiation of etanercept. This patient was also successfully treated by open debridement. However, when etanercept was reinitiated two years after open debridement, infection reoccurred. Immediately, open debridement was performed, prosthesis was removed, and antibiotic-impregnated, cement spacer was inserted. THA was repeated two months after open debridement. Late onset infection developing after THA following etanercept therapy in RA indicates that tumor necrosis factor-alpha blockers should be carefully administered in patients who have undergone THA.

Keywords: Late infection; total hip arthroplasty; tumor necrosis factor-alpha blockers.
\end{abstract}

The efficacy of tumor necrosis factor-alpha (TNF- $\alpha$ ) blockers is well established in patients with rheumatoid arthritis (RA). ${ }^{1}$ However, some published studies have reported a higher risk of surgical site of infection in the presence of TNF- $\alpha$ blocker usage..$^{2,3}$ These surgical site infections commonly occurred within four weeks of surgery. Later occurring infections were considered to be rare. ${ }^{4}$ In this article, we report rare acute onset of late infection after total hip arthroplasty (THA), following TNF- $\alpha$ blocker therapy in two RA patients.

\section{CASE REPORT}

Case 1- A 74-year-old female with RA (Steinbrocker classification: functional class III, stage of disease progression 4) who was first diagnosed in 1973 was treated with non-biological disease-modifying antirheumatic drugs. The patient underwent left THA in 2009. Methotrexate therapy was started in 2010. However, methotrexate therapy caused rash in 2012. Therefore, we stopped methotrexate therapy, and changed the treatment with biological drug. Etanercept (25 mg/week) with steroids (5 mg/day) therapy was started in 2012. Two months later, patient presented again with complaints of left hip pain accompanied by elevated levels of inflammation markers on laboratory evaluation [C-reactive protein (CRP), $26.2 \mathrm{mg} / \mathrm{L}$ (normal value; 0-0.3); white blood cells, 14,100 cell $/ \mathrm{mm} 3$ (normal value; 3,500-9,000)]. Magnetic resonance imaging showed high intensity signal from left hip joint to subcutaneous tissue (Figure 1a, b). Aspiration fluid was pus, and Escherichia coli was detected in culture of joint aspiration. Thus the diagnosis of deep joint infection was confirmed. Open 
debridement with retention of the prosthesis was performed immediately. Cephalosporin had antibiotic sensitivity. Therefore, $2 \mathrm{~g} /$ day of cephalosporin was administered for six weeks. Following this therapy, all clinical symptoms disappeared and laboratory data returned to normal levels. Tacrolimus (2 mg/day) with steroids (5 mg/day) therapy was started, and the patient had improved findings at follow-up (CRP $<0.3 \mathrm{mg} / \mathrm{L})$.

Case 2- A 62-year-old female with RA (Steinbrocker classification: functional class III, stage of disease progression 4) since 1989 was treated with non-biological disease-modifying antirheumatic drugs. Methotrexate therapy was started in 2000. However, methotrexate therapy caused interstitial pneumonitis in 2003 . Therefore, we stopped methotrexate therapy, and changed the treatment with biological drug. Etanercept therapy ( $25 \mathrm{mg} /$ week) was started in 2003. Patient underwent left THA in 2006. Etanercept therapy was discontinued for four weeks prior to THA, and restarted four weeks after THA. However, at postoperative fourth year, patient presented again with complaints of left hip pain accompanied by elevated levels of inflammation markers on laboratory examination [CRP, $8.6 \mathrm{mg} / \mathrm{L}$ (normal value; 0-0.3); white blood cells, 12,200 cell $/ \mathrm{mm}^{3}$ (normal value; 3,500-9,000)]. Methicillin-resistant Staphylococcus aureus was detected in culture of joint aspiration. Open debridement was performed immediately. Vancomycin had antibiotic sensitivity. Therefore, vancomycin was administered for six weeks. Administration dose of vancomycin was adjusted by therapeutic drug monitoring (peak- to-trough concentration: $10-20 \mu \mathrm{g} / \mathrm{mL}$ ). After the end of treatment, tacrolimus (2 mg/day) and prednisolone (5 mg/day) were introduced for the treatment of RA. Progression of RA increased in 2012, and etanercept therapy (25 mg/week) was introduced once again. After two months, patient suddenly presented with complaints of left hip pain accompanied by elevated levels of inflammation markers on laboratory examination (CRP, $3.8 \mathrm{mg} / \mathrm{L}$; white blood cells, 10,800 cells $/ \mathrm{mm}^{3}$ ). Methicillinresistant Staphylococcus aureus was detected in culture of joint aspiration. Immediately, open debridement was performed, prosthesis was removed, antibiotic-impregnated, cement spacer was inserted, and vancomycin was administered for six weeks (Figure 2a). Following conclusion of the treatment, revision THA was performed which reduced progression of the infection (Figure $2 \mathrm{~b}$ ). Tacrolimus (4 mg/day) with prednisolone $(5 \mathrm{mg} /$ day) was introduced for the treatment of RA after THA, and the patient had improved findings at follow-up (CRP $<0.3 \mathrm{mg} / \mathrm{L})$.

\section{DISCUSSION}

A history of previous joint surgery appeared to be an associated risk factor for infection in patients receiving TNF- $\alpha$ blocker therapy (odds ratio $=2.07$ ). ${ }^{5}$ Galloway et al. ${ }^{6}$ reported that exposure to TNF blocker therapy was associated with an increased risk of joint infection in patients with RA. This risk was greatest in the first year of treatment. Furthermore, joint prosthesis was
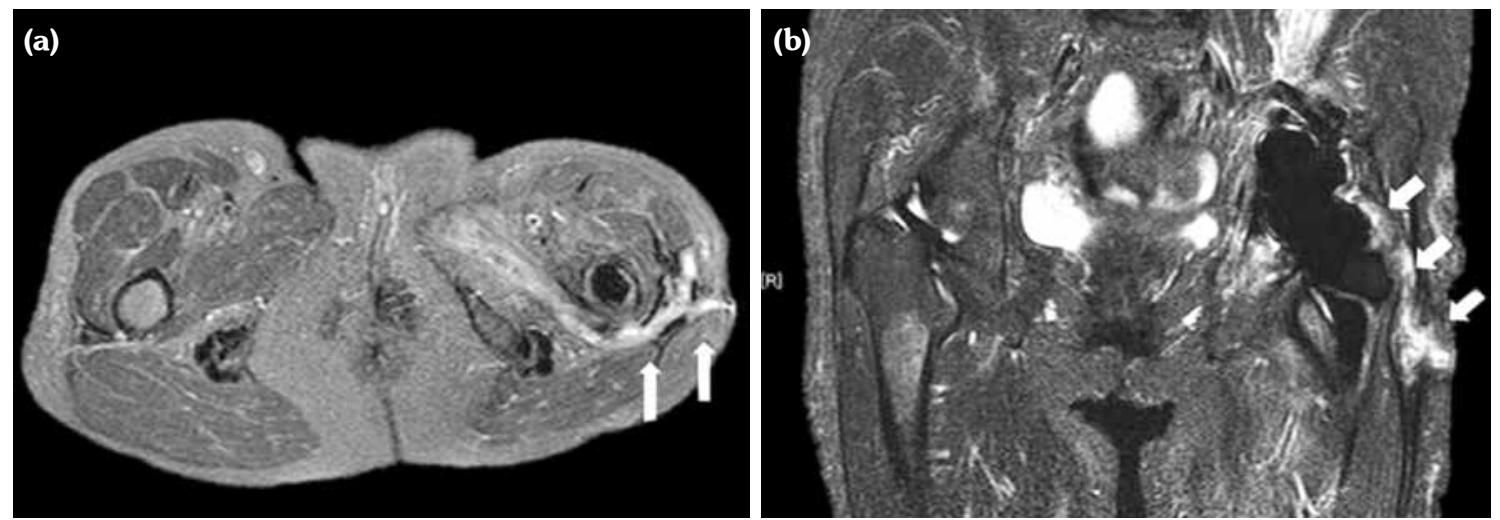

Figure 1. Short $T_{1}$ inversion recovery images of magnetic resonance imaging preoperatively. (a) Axial image (b) Frontal image. 

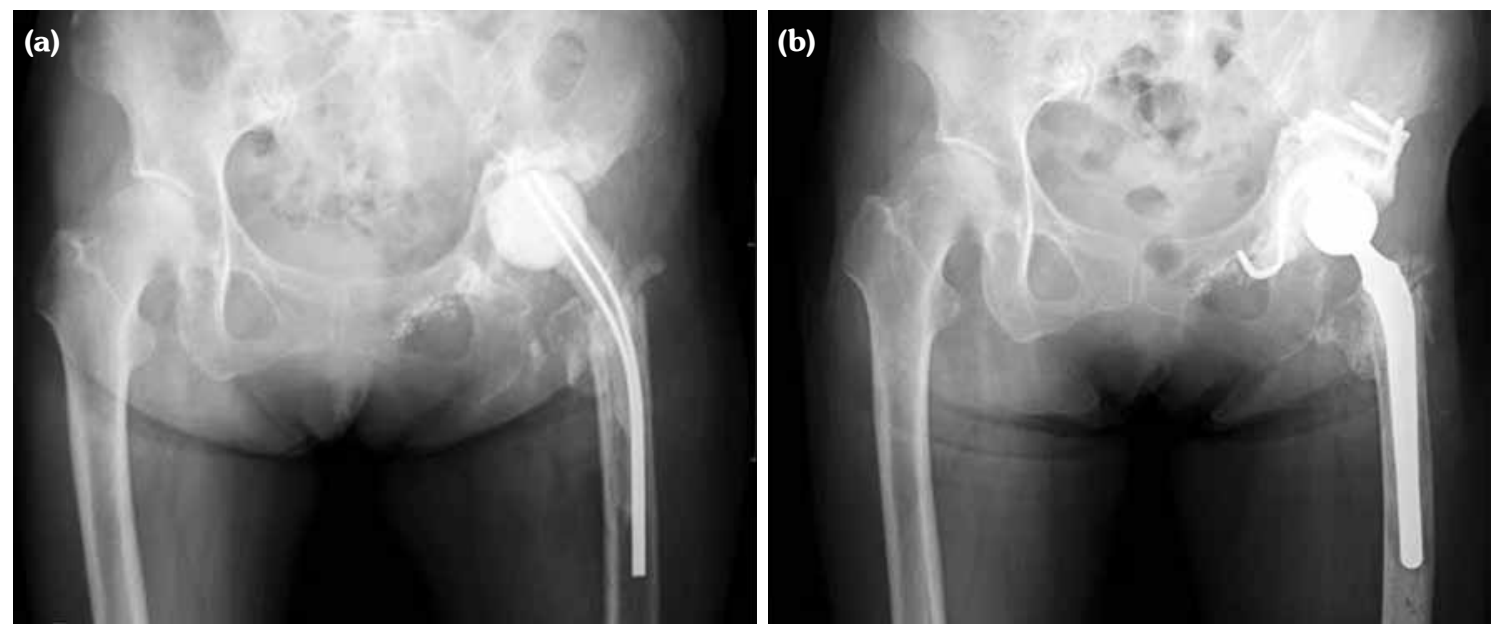

Figure 2. Radiographic findings. (a) After open debridement surgery. (b) After revision total hip arthroplasty.

another key risk factor for infection. Therefore, the authors proposed that antibiotic guidelines should incorporate this information and consider giving specific advice for patients being actively treated with anti-TNF blocker.

Steroids are also associated with an increased risk factor for infection in RA patients treated with TNF- $\alpha$ blockers. ${ }^{5,7}$ Schneeweiss et al. ${ }^{7}$ demonstrated that the use of steroids doubled the rate of severe bacterial infections when compared with methotrexate therapy, independent of previous disease-modifying antirheumatic drug use (odds ratio $=2.1$ ), and demonstrated a clear dose-response relationship. In our first patient, infection after THA occurred following the introduction of TNF- $\alpha$ blocker. The patient was concurrently treated with a steroid. These risk factors may be synergistically related to the onset of the infection.

In cases involving previous infections after total joint arthroplasty, high recurrence rates (10\% at 3 years and $26 \%$ at 10 years) have been reported. ${ }^{8}$ The British Society of Rheumatology has indicated that previous sepsis that remains in situ, after total joint arthroplasty, is a definitive contraindication to TNF- $\alpha$ blocker use. ${ }^{9}$ Our second patient was placed on TNF- $\alpha$ blocker therapy following infection of the tissue surrounding the area of THA. We believe that the patient may have had a micro surgical site infection that remained asymptomatic, in which case, the sudden outbreak of infection as a reoccurrence may not have been due to the immunosuppressive effects of etanercept. Therefore, we believe that TNF- $\alpha$ blocker therapy should not be restarted or administered in case of previous surgical site infection after total joint arthroplasty.

To the best of our knowledge, a limited number of studies have been reported on the treatment of patients with infection after arthroplasty. Instead of biological drug therapy, we advise administration of tacrolimus therapy for patients with infection after arthroplasty. The administration of a TNF- $\alpha$ blocker should be carefully considered and closely followed in patients who have undergone total joint arthroplasty.

\section{Declaration of conflicting interests}

The authors declared no conflicts of interest with respect to the authorship and/or publication of this article.

\section{Funding}

The authors received no financial support for the research and/or authorship of this article.

\section{REFERENCES}

1. Maini RN, Breedveld FC, Kalden JR, Smolen JS, Davis D, Macfarlane JD, et al. Therapeutic efficacy of multiple intravenous infusions of anti-tumor necrosis factor alpha monoclonal antibody combined with low-dose weekly methotrexate in rheumatoid arthritis. Arthritis Rheum 1998;41:1552-63.

2. Giles JT, Bartlett SJ, Gelber AC, Nanda S, Fontaine $\mathrm{K}$, Ruffing $\mathrm{V}$, et al. Tumor necrosis factor inhibitor therapy and risk of serious postoperative orthopedic 
infection in rheumatoid arthritis. Arthritis Rheum 2006;55:333-7.

3. Ruyssen-Witrand A, Gossec L, Salliot C, Luc M, Duclos M, Guignard S, et al. Complication rates of 127 surgical procedures performed in rheumatic patients receiving tumor necrosis factor alpha blockers. Clin Exp Rheumatol 2007;25:430-6.

4. Yurube T, Takahi K, Owaki H, Fuji T, Kurosaka M, Doita M. Late infection of total knee arthroplasty inflamed by anti-TNFalpha, Infliximab therapy in rheumatoid arthritis. Rheumatol Int 2010;30:405-8.

5. Salliot C, Gossec L, Ruyssen-Witrand A, Luc M, Duclos M, Guignard S, et al. Infections during tumour necrosis factor-alpha blocker therapy for rheumatic diseases in daily practice: a systematic retrospective study of 709 patients. Rheumatology (Oxford) 2007;46:327-34.

6. Galloway JB, Hyrich KL, Mercer LK, Dixon WG, Ustianowski AP, Helbert M, et al. Risk of septic arthritis in patients with rheumatoid arthritis and the effect of anti-TNF therapy: results from the British Society for Rheumatology Biologics Register. Ann Rheum Dis 2011;70:1810-4.

7. Schneeweiss S, Setoguchi S, Weinblatt ME, Katz JN, Avorn J, Sax PE, et al. Anti-tumor necrosis factor alpha therapy and the risk of serious bacterial infections in elderly patients with rheumatoid arthritis. Arthritis Rheum 2007;56:1754-64.

8. den Broeder AA, Creemers MC, Fransen J, de Jong E, de Rooij DJ, Wymenga A, et al. Risk factors for surgical site infections and other complications in elective surgery in patients with rheumatoid arthritis with special attention for anti-tumor necrosis factor: a large retrospective study. J Rheumatol 2007;34:689-95.

9. Ledingham J, Deighton $\mathrm{C}$. Update on the British Society for Rheumatology guidelines for prescribing TNFalpha blockers in adults with rheumatoid arthritis (update of previous guidelines of April 2001). Rheumatology (Oxford) 2005;44:157-63. 